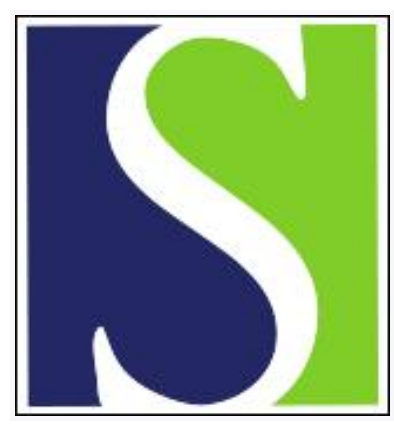

Scand J Work Environ Health 2008;34(2):133-141

https://doi.org/10.5271/sjweh.1224

Issue date: 31 Apr 2008

Salivary endothelin and vascular disorders in vibration-exposed workers

by Bovenzi M, D'Agostin F, Rui F, Ambrosi L, Zefferino R

Affiliation: Clinical Unit of Occupational Medicine, Department of Public Health Sciences, University of Trieste, Centro Tumori, Via della Pietà 19, I-34129 Trieste, Italy. bovenzi@units.it

The following article refers to this text: 2016;42(2):103-124

Key terms: cold challenge; salivary endothelin; vascular disorder; vibration exposure; vibration-exposed worker; white finger; worker

This article in PubMed: www.ncbi.nlm.nih.gov/pubmed/18493696 


\title{
Salivary endothelin and vascular disorders in vibration-exposed workers
}

\author{
by Massimo Bovenzi, MD, ${ }^{1}$ Flavia D'Agostin, MD, ${ }^{1}$ Francesca Rui, MD, ${ }^{1}$ Luigi Ambrosi, MD, ${ }^{2}$ Roberto Zef- \\ ferino, $M D^{3}$
}

\begin{abstract}
Bovenzi M, D’Agostin F, Rui F, Ambrosi L, Zefferino R. Salivary endothelin and vascular disorders in vibrationexposed workers. Scand J Work Environ Health. 2008;34(2):133-141.

Objectives This study investigated the relation between salivary endothelin, vibration exposure, and vascular disorders in a group of forestry workers.

Methods Altogether 54 forestry workers and 52 controls underwent a medical examination and a cold test with measurement of the percentage of change in finger systolic blood pressure after finger cooling from $30^{\circ} \mathrm{C}$ to $10^{\circ} \mathrm{C}$ $\left(\mathrm{FSBP} \%_{10^{\circ}}\right)$. Salivary endothelin concentration $\left(\mathrm{ET}_{1-21}\right.$, in $\left.\mathrm{fmol} / \mathrm{ml}\right)$ was measured by a commercially available enzyme-linked immunosorbent assay before and after the cold challenge. The anamnestic diagnosis of vibrationinduced white finger (VWF), assisted by color charts, was based on the Stockholm Workshop criteria.

Results Six forestry workers (11\%) and one control (2\%) reported white fingers. Before the cold challenge, the salivary $\mathrm{ET}_{1-21}$ concentration was significantly greater in the VWF workers than in the controls $(\mathrm{P}=0.036)$. The cold response of digital arteries was stronger in the VWF workers than in the controls $(\mathrm{P}<0.001)$ and the asymptomatic forestry workers $(\mathrm{P}=0.008)$. After the cold test, there was a small, not significant, increase in the salivary $\mathrm{ET}_{1-21}$ concentration in both the controls and the forestry workers. For the latter, the salivary $\mathrm{ET}_{1-21}$ concentration was significantly associated with both daily and total operating time with vibrating tools. A significant inverse relation between $\mathrm{FSBP} \%_{10^{\circ}}$ and the salivary $\mathrm{ET}_{1-21}$ concentration was observed for the forestry workers with an abnormal cold response in their digital arteries.

Conclusions This study showed an association between salivary $\mathrm{ET}_{1-21}$ concentration, daily and cumulative vibration exposure, and vascular disorders in the fingers of professional forestry workers. Since $\mathrm{ET}_{1-21}$ can induce powerful and long-lasting constriction of human vessels, these findings suggest a possible role of this vasopeptide in the pathogenesis of VWF.
\end{abstract}

Key terms cold challenge; salivary endothelin; vibration exposure; white finger.

Vibration-induced white finger (VWF) is a secondary form of Raynaud's phenomenon that occurs in workers with prolonged exposure to hand-transmitted vibration from power tools. The pathogenesis of VWF is not yet fully understood. Both intrinsic (local) and extrinsic (neural or endocrine) vasoregulatory mechanisms are believed to be involved in the pathogenesis of VWF (1-3). A dominant role for centrally mediated vasomotor mechanisms during an attack of Raynaud's phenomenon has been suggested $(1,2)$. Among local factors, a possible role for endothelin, a 21-amino acid peptide with potent and long-lasting vasoconstrictor activity, has been reported in some studies, even though experimental and epidemiologic investigations of serum endothelin in vibration-exposed workers have produced contrasting results (4-9). Since the release of endogenous endothelin is predominantly directed towards the vascular smooth muscle cells to contribute to the maintenance of basal vascular tone, and only $20 \%$ of endothelin is directed towards the vessel lumen, it has been argued that serum endothelin concentrations may not reflect the activation of this paracrine or autocrine vasopeptide (10). Recently, the use of salivary biomarkers has greatly increased in occupational medicine, and fields of application include heavy metals (lead, cadmium), stress (cortisol, chromogranin A, immunoglobulin A), and immunity (lysozyme, immunoglobulin A) (11). Salivary endothelin $\left(\mathrm{ET}_{1-21}\right)$ has been found to be a suitable biomarker in the assessment of patients with chronic heart failure, oral cancer, and upper gastrointestinal

1 Clinical Unit of Occupational Medicine, Department of Public Health Sciences, University of Trieste, Trieste, Italy.

2 Salvatore Maugeri Foundation, IRCCS, Cassano delle Murge, Bari, Italy.

3 Department of Medical and Occupational Health Sciences, University of Foggia, Foggia, Italy.

Reprint requests to: Professor M Bovenzi, Clinical Unit of Occupational Medicine, Department of Public Health Sciences, University of Trieste, Centro Tumori, Via della Pietà 19, I-34129 Trieste, Italy. [E-mail: bovenzi@units.it] 
diseases (12-14). To our knowledge, no earlier studies have addressed the correlation between salivary $\mathrm{ET}_{1-21}$ and occupational (vascular) diseases.

The aim of this study was to investigate the relation between salivary $\mathrm{ET}_{1-21}$, vibration exposure, and vibrationinduced vascular disorders in a group of forestry workers. This cross-sectional survey was nested in a prospective cohort study of the dose-response relationship for health disorders among vibration-exposed workers recruited in a 4-year research project funded by the European Union commission known by the acronym VIBRISKS (risks of occupational vibration exposures) (15).

\section{Study population and methods}

\section{Study population and medical investigation}

In January-February of 2007, the occurrence of VWF, the cold response of digital arteries, and salivary $\mathrm{ET}_{1-21}$ were investigated in a group of forestry workers. The study population included all 72 male forestry workers operating chain saws and brush saws in a public company of northeastern Italy. Owing to organizational problems due to time schedules at the workplace, saliva samples could be collected from 54 forestry workers (75\%). The lost workers $(\mathrm{N}=18)$ did not differ significantly from the participants in the study with respect to age, smoking and drinking habits, and measures of vibration exposure. None of them suffered from VWF.

Altogether 56 male workers employed by the same company (inspectors, supervisors), and unexposed to hand-transmitted vibration, served as controls. Saliva sample collections were available for 52 controls $(93 \%)$. Four men were lost for incompatibility with the work schedule.

Each participant signed a written informed consent for participation in the study, which was approved by the local ethics committee.

The forestry workers and the controls were interviewed about their personal, work, and health histories using a structured questionnaire developed within the European research project VIBRISKS (15). Both the forestry workers and the controls were questioned about smoking, alcohol consumption, metabolic (eg, diabetes), cardiovascular (eg, arterial hypertension) and neurological (eg, sensorineural disturbances, carpal tunnel syndrome) disorders, previous musculoskeletal injuries, and the use of medicines. Ex-smokers were classified as nonsmokers if they had stopped smoking at least 2 years earlier. The same time period was applied for ex-drinkers to be classified as nondrinkers. Each participant underwent a physical examination focused on the vascular, neurological, and musculoskeletal systems of the upper limbs.
The anamnestic diagnosis of VWF was based on the following criteria, established at the Stockhom Workshop '94 (16): (i) a positive history of cold-provoked episodes of well-demarcated blanching in one or more fingers after the exclusion of primary Raynaud's phenomenon or other probable causes of secondary Raynaud's phenomenon and (ii) first appearance of finger blanching after the start of occupational exposure to hand-transmitted vibration and experience of VWF attacks during the last 2 years.

To assist the diagnosis of Raynaud's phenomenon, color charts were shown to the workers at the end of the medical interview. The charts consisted of a series of photographs illustrating various degrees of blanching, cyanosis, or redness of the fingers and hands, according to the scheme proposed by Maricq \& Weinrich (17), partially modified. A diagnosis of finger whiteness was considered positive when the participant indicated that the photographs displayed well-demarcated blanching of the fingers. White patching of the hand palm, cyanosis of the fingers, or acrocyanosis alone were not considered to be sufficient for a diagnosis of Raynaud's phenomenon.

\section{Cold test}

The cold test was performed in a room with an ambient temperature of $20-22^{\circ} \mathrm{C}$. The cold challenge consisted of strain-gauge plethysmographic measurement of finger systolic blood pressure (FSBP) during local cooling according to the technique recommended by the international standard ISO 14835-2 (18). Arm systolic blood pressure (ASBP) was measured by an auscultatory technique using a mercury sphygmomanometer and a standard rubber cuff $(12 \times 23 \mathrm{~cm})$.

The following systolic pressure indices were calculated:

1. The change of systolic blood pressure in a test finger at $10^{\circ} \mathrm{C}\left(\mathrm{FSBP}_{\mathrm{t}, 10^{\circ}}\right)$ as the percentage of the pressure at $30^{\circ} \mathrm{C}\left(\mathrm{FSBP}_{\mathrm{t}, 30^{\circ}}\right)$, corrected for the change of pressure in a reference finger during the examination $\left(\mathrm{FSBP}_{\mathrm{ref}, 30^{\circ}}-\mathrm{FSBP}_{\text {ref }, 10^{\circ}}\right)$ :

$$
\begin{aligned}
& \mathrm{FSBP}_{10^{\circ}}=\left(\mathrm{FSBP}_{\mathrm{t}, 10^{\circ}} \times 100\right) /\left[\mathrm{FSBP}_{\mathrm{t}, 30^{\circ}}-\left(\mathrm{FSBP}_{\mathrm{ref}, 30^{\circ}}\right.\right. \\
& \left.\left.-\mathrm{FSBP}_{\mathrm{ref}, 10^{\circ}}\right)\right](\%) .
\end{aligned}
$$

2. The digital pressure index in the test finger at $30^{\circ} \mathrm{C}$ $\left(\mathrm{DPI}_{30^{\circ}}\right.$ ), calculated as the ratio of FSBP to ASBP:

$$
\mathrm{DPI}_{30^{\circ}}=\left(\mathrm{FSBP}_{\mathrm{t}, 30^{\circ}} \times 100\right) / \mathrm{ASBP}_{30^{\circ}}(\%) . \quad \text { (equation 2) }
$$

To avoid nicotine-induced vasoconstrictive effects on the digital vessels, tobacco users refrained from smoking for at least 2 hours before being tested. The participants were requested to abstain from consuming alcoholic beverages since the evening preceding the day of the cold test. 


\section{Saliva sample collection}

The participants were asked in advance not to eat or drink (except for water) for 1 hour before the saliva collection to minimize possible food debris and the stimulation of salivation.

Before the saliva sample collection, the participants rested in a seated position for at least 20 minutes according to current recommendations (12). A saliva sample was then collected over 2-3 minutes with a Salivette (Sarstedt, Nümbrecht, Germany). Saliva samples were obtained before and after the cold test using the same procedure. Since this investigation took place in an outside research station, the saliva samples were kept at $4^{\circ} \mathrm{C}$ for various time periods (1-4 hours) and then stored at $-20^{\circ} \mathrm{C}$ in a hospital laboratory for later analysis.

In addition to $\mathrm{ET}_{1-21}$, saliva fluid contains big $\mathrm{ET}$ (a 39-amino acid precursor of $\mathrm{ET}_{1-21}$ ) and ET-converting enzyme (ECE), which converts big ET to mature $\mathrm{ET}_{1-21}$. It has been shown that $\mathrm{ET}_{1-21}$ concentrations in saliva tend to increase with the increase of sample storage time because of ECE activity (10). Xiang et al (10), who investigated the physical and physiological determinants of $\mathrm{ET}_{1-21}$ concentrations in human saliva, reported no significant changes in $\mathrm{ET}_{1-21}$ concentrations in saliva samples stored at $4^{\circ} \mathrm{C}$ for the range of storage times used in our study (10). Moreover, they did not find significant diurnal variations in $\mathrm{ET}_{1-21}$ concentrations in saliva samples.

\section{Assay of salivary endothelin}

The laboratory personnel were blind to the exposure conditions of the participants, their health status, and the sequence of saliva samples (before or after the cold challenge).

Salivary fluid was extracted by centrifugation at $1000 \mathrm{~g}$ for 5 minutes. Salivary $\mathrm{ET}_{1-21}$ was measured by a commercially available enzyme-linked immunosorbent assay (ELISA) (Biomedica Medizinprodukte, Wien, Austria). All of the samples and calibrators were assayed in duplicate. According to the manufacturer, the cross-reactivity of the ELISA was $100 \%$ for both endothelin- 1 and endothelin-2, <5\% for endothelin-3, and $<1 \%$ for big endothelin. The lower detection limit was $0.02 \mathrm{fmol} / \mathrm{ml}$. The intraassay variability (as coefficient of variation) was $\leq 4.0 \%$, and the interassay variability was $\leq 6.0 \%$. The recovery rate for endothelin- 1 in saliva was $96 \%$ with a sample concentration of $1 \mathrm{fmol} / \mathrm{ml}$. It has been reported that, in spite of the presence of crossreactivity to other endothelin isoforms in saliva samples, the assay measures primarily endothelin-1 (10). To check the performance of the method in our laboratory, we tested 18 samples in the same assay and 18 samples in three different assays. Three samples were used for each of three independent experiments. The mean value was 1.697 (SD 0.079) fmol/ml and 1.617 (SD 0.099) $\mathrm{fmol} / \mathrm{ml}$ for the intraassay and interassay determinations, respectively. The intraassay imprecision (as coefficient of variation) was $4.7 \%$, and the interassay imprecision was $6.1 \%$.

The assays of $\mathrm{ET}_{1-21}$ in salivary samples were performed according to the manufacturer's kit instructions. In brief, samples (standard, control, and blank) were incubated with detection antibody (monoclonal mouse anti-endothelin antibody) at room temperature for 24 hours. After washing, conjugate anti-mouse immunoglogulin $\mathrm{G}(\mathrm{IgG})$ antibody-HRPO (horseradish peroxidase) was added and incubated at room temperature for 1 hour. After additional washing, a TMB (tetramethylbenzidine) solution was added and incubated for 30 minutes at room temperature in the dark. Finally, a stop solution was added, and the absorbance was measured at $450 \mathrm{~nm}$ with reference to $620 \mathrm{~nm}$.

\section{Measurement and assessment of vibration exposure}

Vibration was measured for the brush saws $(\mathrm{N}=5)$ and chain saws $(\mathrm{N}=13)$ used by the forestry workers. Vibration measurements were made in the field during actual operating conditions performed by skilled workers. Vibration was measured in three orthogonal directions according to the ISO 5349-1 procedure (19). From the one-third octave band frequency spectra $(6.3-1250 \mathrm{~Hz})$, the root-mean-square (rms) of the frequency-weighted accelerations $\left(\mathrm{a}_{\mathrm{hw}}\right)$ were obtained. The root-sum of squares of the frequency-weighted rms acceleration values $\left(a_{v}\right)$ for the $x-, y$ - and z-axes $\left[a_{v}=\left(a_{h w x}{ }^{2}+a_{h w y}{ }^{2}+a_{h w z}\right)^{2 / 2}\right]$ averaged $5.3 \mathrm{~m} / \mathrm{s}^{2}$ (front handle) and $5.5 \mathrm{~m} / \mathrm{s}^{2}$ (rear handle) for the brush saws and $4.9 \mathrm{~m} / \mathrm{s}^{2}$ (front handle) and $5.6 \mathrm{~m} / \mathrm{s}^{2}$ (rear handle) for the chain saws.

Daily vibration exposure was assessed in terms of the 8-hour acceleration magnitude of the energy-equivalent frequency-weighted rms, $\mathrm{A}(8)$, according to the European directive for mechanical vibration (20):

$$
\mathrm{A}(8)=\mathrm{a}_{\mathrm{v}}\left(\mathrm{T}_{\mathrm{e}} / \mathrm{T}_{0}\right)^{1 / 2}\left(\mathrm{~m} / \mathrm{s}^{2} \mathrm{rms}\right),
$$

(equation 3)

where $T_{e}$ is the daily duration of exposure to vibration $a_{v}$ in hours and $\mathrm{T}_{0}$ is the reference duration of 8 hours.

Questionnaire data, information obtained in interviews with employees and employers, and company records were used to estimate the total operating time (hours) with vibrating tools.

The use of vibrating tools during spare time was also investigated. Both the forestry workers (36\%) and the controls (30\%) reported leisure-time use of power tools (mainly brush saws for gardening, more rarely chain saws). It was difficult to quantify the extra exposure to vibration for each participant since operating vibrating tools outside work was not regular over a typical calendar year. However, when this additional exposure factor 
was included as a dichotomous variable (no, yes) in the data analysis, it did not show any significant association with the outcomes of interest.

\section{Statistical methods}

The data analysis was performed with the statistical software Stata v. 10.0 SE (Stata Corporation, State College, TX, USA, 2007). Continuous variables were summarized using the mean as a measure of central tendency and the standard deviation (SD) or the standard error (SE) as measures of dispersion.

The difference between paired observations was tested by the Wilcoxon's signed-ranks test. The MannWhitney test was used to compare two independent groups. The difference between more than two independent groups was tested with the Kruskal-Wallis one-way analysis of variance and multiple comparisons. To test for trend across ordered variables, the Cuzick's nonparametric test, an extension of the Wilcoxon rank-sum test, was used.

Multivariate linear regression was used to study the association between outcomes (salivary ET $_{1-21}$ or FSBP $\%_{10^{\circ}}$ ) and several individual and exposure variables. A P-value of 0.05 was chosen as the limit of statistical significance.

\section{Results}

\section{Characteristics of the study population}

Table 1 presents the individual and exposure characteristics of the study populations. Age, body mass index, smoking and drinking habits, job seniority, and the base values of blood pressure and heart rate were similar in the study groups. Six forestry workers $(11 \%)$ reported VWF in the medical interview (assisted by color charts). Daily and total vibration exposure $[\mathrm{A}(8)$, exposure duration] was generally greater among the forestry workers affected with VWF than among those without VWF, but the difference was not significant.

Altogether 29 forestry workers (53.7\%) and 16 controls $(30.8 \%)$ reported paresthesias (tingling) in the fingers and hands $(\mathrm{P}=0.02)$. No participant was found to be affected with symptoms or signs of carpal tunnel syndrome. In the physical examination, mild arterial hypertension was found for two forestry workers without VWF and three controls; they were not on any medication.

One control was affected by Raynaud's phenomenon $(2 \%)$. Neither the control nor the VWF workers suffered from arterial hypertension or metabolic disorders such as diabetes or used medicines.

None of the forestry workers or controls were excluded from the data analysis.

\section{Salivary endothelin ${ }_{1-21}$ at baseline}

Figure 1 shows the salivary $\mathrm{ET}_{1-21}$ concentrations before and after the cold challenge among the controls and the forestry workers according to their VWF status. In the base conditions, there was a significant difference between the groups $(\mathrm{P}=0.01)$. A multicomparison test showed that the base salivary $\mathrm{ET}_{1-21}$ concentrations were significantly greater in the VWF workers than in the controls $(\mathrm{P}=0.036)$. No significant differences were observed between the controls and the group without VWF $(\mathrm{P}=0.35)$ or between the groups without and with

Table 1. Characteristics of the study population. The forestry workers have been divided into two groups according to their status with respect to vibration-induced white finger (VWF). $[A(8)=8$-hour energy-equivalent frequency-weighted acceleration magnitude, rms $=$ root mean square]

\begin{tabular}{|c|c|c|c|c|c|c|c|c|c|c|c|c|}
\hline \multirow[t]{3}{*}{ Characteristic } & \multicolumn{4}{|c|}{ Controls ( $\mathrm{N}=52)$} & \multicolumn{8}{|c|}{ Forestry workers } \\
\hline & \multirow[b]{2}{*}{$\mathrm{N}$} & \multirow[b]{2}{*}{$\%$} & \multirow[b]{2}{*}{ Mean } & \multirow[b]{2}{*}{$\mathrm{SD}$} & \multicolumn{4}{|c|}{ Without VWF (N=48) } & \multicolumn{4}{|c|}{ With VWF $(\mathrm{N}=6)$} \\
\hline & & & & & $\mathrm{N}$ & $\%$ & Mean & SD & $\mathrm{N}$ & $\%$ & Mean & SD \\
\hline Age (years) & - & . & 41.7 & 6.7 & - & . & 44.7 & 6.1 & - & . & 43.0 & 5.1 \\
\hline Body mass index $\left(\mathrm{kg} / \mathrm{m}^{2}\right)$ & - & - & 25.1 & 2.7 & - & . & 26.0 & 3.0 & - & - & 26.5 & 3.2 \\
\hline Smoking & 6 & 11.4 & - & - & 14 & 29.2 & - & - & 2 & 33.3 & - & . \\
\hline Drinking & 40 & 76.9 & - & - & 37 & 80.4 & - & - & 4 & 80.0 & - & . \\
\hline Systolic blood pressure (mm Hg) & - & . & 126 & 13 & - & . & 129 & 10 & - & . & 125 & 8 \\
\hline Diastolic blood pressure (mm Hg) & - & . & 81 & 7 & - & . & 85 & 8 & - & . & 83 & 7 \\
\hline Heart rate (beats/minute) & - & - & 63 & 7 & - & . & 64 & 7 & - & . & 63 & 8 \\
\hline Job seniority (years) & - & - & 18.0 & 4.8 & - & - & 14.2 & 3.8 & - & - & 20.3 & 5.5 \\
\hline $\mathrm{A}(8)\left(\mathrm{m} / \mathrm{s}^{2} \mathrm{rms}\right)$ & - & . & . & . & - & . & 2.5 & 0.6 & - & . & 2.9 & 0.1 \\
\hline Daily exposure duration (hours) & - & . & . & . & - & . & 2.3 & 1.7 & - & . & 2.5 & 1.2 \\
\hline Total exposure duration (hours) & - & . & . & . & - & . & 7110 & 5250 & - & . & 10350 & 1520 \\
\hline
\end{tabular}


VWF $(\mathrm{P}=0.09)$. None of the VWF patients suffered from diseases that may have affected the salivary $\mathrm{ET}_{1-21}$ concentration, such as chronic heart failure, inflammatory gastrointestinal disease, rheumatoid arthritis, or Sjögren's syndrome.

\section{Cold test results}

Table 2 presents the cold test results. The cold response of digital arteries was significantly stronger (ie, reduction of $\mathrm{FSBP}_{10^{\circ}}$ ) in the forestry workers with VWF than in the controls $(\mathrm{P}<0.001)$ and the asymptomatic forestry workers $(\mathrm{P}=0.008)$. There was no significant difference between the controls and the forestry workers without VWF $(\mathrm{P}=0.08)$. The FSBP in the test finger at $30^{\circ} \mathrm{C}\left(\mathrm{FSBP}_{\mathrm{t}, 30^{\circ}}\right)$ and the digital pressure index at $30^{\circ} \mathrm{C}$ $\left(\mathrm{DPI}_{30^{\circ}}\right)$ did not differ between the groups. Overall, the $\mathrm{DPI}_{30^{\circ}}$ values suggested normal pressure gradients from the arm to the finger in the baseline conditions of all the groups.

\section{Salivary endothelin $n_{1-21}$ after cold challenge}

After the cold test there was a small, not significant increase in the salivary $\mathrm{ET}_{1-21}$ concentration of both the controls [mean change 0.10 (SE 0.13) fmol/ml] and the forestry workers [mean change 0.07 (SE 0.12$) \mathrm{fmol} / \mathrm{ml}$ ], with no difference between the symptomatic and asymptomatic participants. After the cold challenge, the difference in the salivary $\mathrm{ET}_{1-21}$ concentrations between the groups (controls, forestry workers without VWF, and forestry workers with VWF) was significant at a probability level similar to that observed in the baseline conditions $(\mathrm{P}<0.005)$ (figure 1$)$.

\section{Relation between salivary endothelin $n_{1-21}$, vibration exposure and cold challenge}

With the use of the controls as the reference category, the baseline concentrations of the salivary $\mathrm{ET}_{1-21}$ of the forestry workers was significantly associated with either daily vibration exposure $[\mathrm{A}(8)]$ greater than $2.5 \mathrm{~m} / \mathrm{s}^{2} \mathrm{rms}$ or a total operating time with vibrating tools in excess of 8000 hours (table 3 ). There was a significant trend across the ordered groups for both $\mathrm{A}(8)(\mathrm{P}<0.001)$ and the total exposure duration $(\mathrm{P}<0.01)$.

The relation between salivary $\mathrm{ET}_{1-21}$ and cold-induced digital arterial hyperresponsiveness was assessed in a subgroup of forestry workers with an abnormal response to cold provocation in the digital arteries. In the control group of this study, FSBP $\%_{10}$ averaged 95.8 (SD 10.2). On the assumption that $\mathrm{FSBP} \%_{10^{\circ}}<75 \%$ (mean-2SD) was the lower normal limit, nine forestry workers $(16.7 \%)$ had an abnormal cold test.

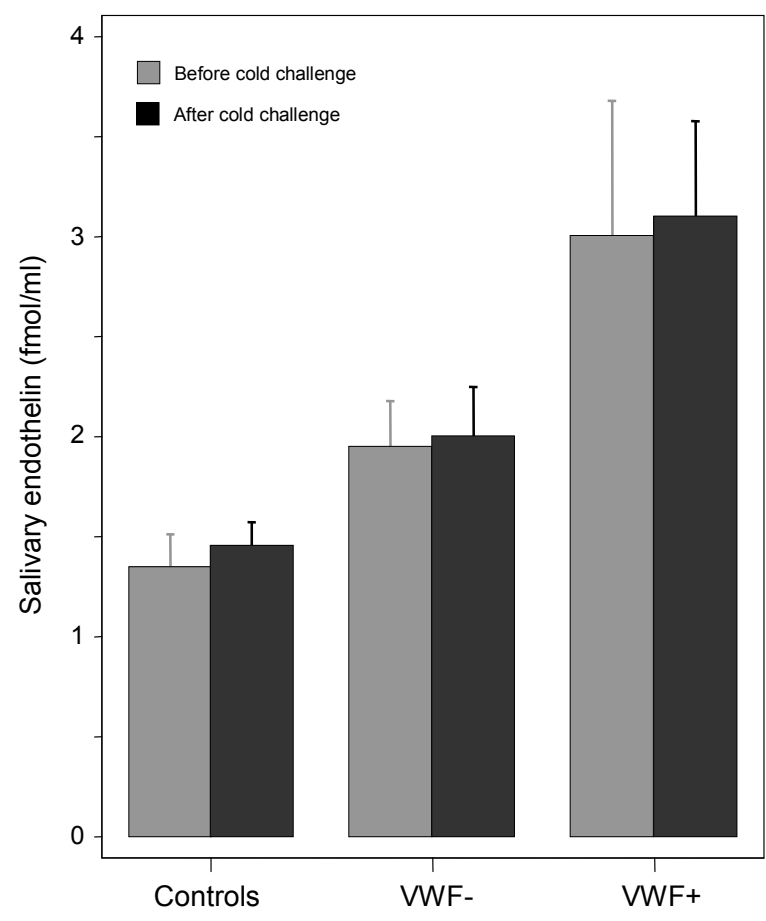

Figure 1. Mean and standard errors of the means (SE) of the salivary endothelin concentration before and after cold challenge among the controls and forestry workers according their status with respect to vibration-induced white finger (VWF). Before the cold challenge: Kruskal-Wallis test: $\mathrm{P}=0.01$ (multicomparison test: controls versus forestry workers without VWF $P=0.35$, controls versus forestry workers with VWF $P=0.036$, forestry workers without VWF versus forestry workers with VWF $P=0.09)$. After the cold challenge: Kruskal-Wallis test: $P<0.005$ (multicomparison test: controls versus forestry workers without VWF $P=0.17$, controls versus forestry workers with VWF $P=0.035$, forestry workers without VWF versus forestry workers with VWF $\mathrm{P}=0.19$ ).

Table 2. Results of the cold test for the controls and the forestry workers according to their vibration-induced white finger (VWF) status. See the text for the definition of finger systolic blood pressure (FSBP) and digital pressure indices (DPI). ${ }^{\mathrm{a}}$

\begin{tabular}{|c|c|c|c|c|c|}
\hline \multirow[t]{3}{*}{ Outcome } & \multirow{2}{*}{\multicolumn{2}{|c|}{$\begin{array}{c}\text { Controls } \\
(\mathrm{N}=52)\end{array}$}} & \multicolumn{3}{|c|}{ Forestry workers } \\
\hline & & & \multicolumn{2}{|c|}{$\begin{array}{l}\text { Without VWF } \\
\quad(\mathrm{N}=48)\end{array}$} & $\begin{array}{l}\text { With VWF } \\
\qquad(N=6)\end{array}$ \\
\hline & Mean & SD & Mean & SD & Mean SD \\
\hline $\mathrm{FSBP}_{\mathrm{t}, 30^{\circ}}(\mathrm{mm} \mathrm{Hg})$ & 120 & 15.1 & 118 & 16.1 & 113 \\
\hline $\mathrm{DPI}_{30^{\circ}}(\%)$ & 95.8 & 8.7 & 93.9 & 11.1 & $95.6 \quad 8.4$ \\
\hline FSBP $\%_{10^{\circ}}(\%)$ & 95.8 & 10.2 & 88.6 & 16.5 & $\begin{array}{lll}65.9 \text { a } & 39.7\end{array}$ \\
\hline
\end{tabular}

a Kruskal-Wallis one-way analysis of variance: $\mathrm{P}=0.0002$ (multicomparison test: $P=0.08$ for controls versus forestry workers without VWF; $P<0.001$ for controls versus forestry workers with VWF; $P=0.008$ for forestry workers without VWF versus forestry workers with VWF).

After adjustment for age and smoking habits, a significant inverse relation between $\mathrm{FSBP} \%_{10^{\circ}}$ and baseline salivary $\mathrm{ET}_{1-21}$ was observed for the participants with cold hyperreactivity in their digital arteries (table 4). There were no significant interactions between $\mathrm{ET}_{1-21}$ 
Table 3. Multivariate linear regression of salivary endothelin with respect to the daily vibration exposure and total exposure duration of the forestry workers when the controls were used as the reference category. Regression coefficients were adjusted according to age and smoking. $[A(8)=8$-hour energy-equivalent frequencyweighted acceleration magnitude, rms = root mean square, $95 \%$ $\mathrm{Cl}=95 \%$ confidence interval]

\begin{tabular}{lcc}
\hline Model & \multicolumn{2}{c}{ Salivary endothelin (fmol/ml) } \\
\cline { 2 - 3 } & $\begin{array}{c}\text { Regression } \\
\text { coefficient }\end{array}$ & $95 \% \mathrm{Cl}$ \\
\hline Model 1 & & \\
Intercept & 1.05 & $-0.91-3.02$ \\
$\mathrm{~A}(8)\left(\mathrm{m} / \mathrm{s}^{2} \mathrm{rms}\right)$ & & \\
$<2.5(\mathrm{~N}=17)$ & 0.56 & $-0.27-1.38$ \\
$2.5-3.5(\mathrm{~N}=19)$ & 0.89 & $0.08-1.70^{\mathrm{a}}$ \\
$>3.5(\mathrm{~N}=18)$ & 0.98 & $0.12-1.84^{\mathrm{a}}$ \\
Model 2 & & \\
Intercept & 1.07 & $-0.91-3.05$ \\
Total exposure duration (hours) & & \\
$<5000(\mathrm{~N}=18)$ & 0.73 & $-0.09-1.55$ \\
$5000-8000(\mathrm{~N}=19)$ & 0.76 & $-0.05-1.57$ \\
$>8000(\mathrm{~N}=17)$ & 0.95 & $0.08-1.82^{\mathrm{a}}$ \\
\hline
\end{tabular}

a $P=0.03$

Table 4. Multivariate linear regression of finger systolic blood pressure at $10^{\circ} \mathrm{C}\left(\mathrm{FSBP} \%_{10}\right)$ with respect to individual characteristics and salivary endothelin in a subgroup of forestry workers $(\mathrm{N}=9)$ with an abnormal response to cold provocation in the digital arteries (FSBP $\left.\%_{10}<75 \%\right)$. (95\% Cl $=95 \%$ confidence interval)

\begin{tabular}{|c|c|c|}
\hline \multirow[t]{2}{*}{ Predictor } & \multicolumn{2}{|c|}{ FSBP $\%_{10^{\circ}}(\%)$} \\
\hline & Regression coefficient & $95 \% \mathrm{Cl}$ \\
\hline Intercept & 140 & $91.6-189$ \\
\hline Age $\left(\right.$ year $\left.\times 10^{-1}\right)$ & -15.5 & $-26.3--4.7^{\mathrm{a}}$ \\
\hline Smoking (no, yes) & 10.7 & $-4.6-26.1$ \\
\hline Salivary endothelin (fmol/ml) & -9.7 & $-14.3--5.0^{b}$ \\
\hline
\end{tabular}

a $P=0.02$.

b $P=0.007$.

and age or between $\mathrm{ET}_{1-21}$ and smoking. Similar results were obtained when FSBP\% $\%_{10^{\circ}}$ was regressed for the salivary $\mathrm{ET}_{1-21}$ measured after the cold challenge (results not shown).

\section{Discussion}

The findings of this study suggest an association between salivary $\mathrm{ET}_{1-21}$ concentration, vibration exposure, and vascular disorders in the fingers of professional forestry workers. Since there are no earlier studies of salivary $\mathrm{ET}_{1-21}$ and exposure to hand-transmitted vibration, a comparison was attempted between our findings and those of previous investigations of serum endothelin in vibration-exposed workers. In a series of case reports on Czech vibration-exposed workers from various industrial sectors, the highest concentrations of serum $\mathrm{ET}_{1-21}$ were measured in the persons with more-advanced stages of vasospastic disorders (6). In a clinical study of Japanese patients with vibration syndrome, the mean value of plasma $\mathrm{ET}_{1-21}$ was greater for those with VWF than for patients without VWF and normal controls (8). In contrast, a study of stonemasons and quarrymen reported lower baseline concentrations of serum $\mathrm{ET}_{1-21}$ in VWF cases than in exposed people with no vascular symptoms or unexposed controls (9). Similar findings were observed in an investigation of acute effects of riveting, in which plasma $\mathrm{ET}_{1-21}$ concentrations before and after a workshift were slightly lower in the riveters than in their matched controls (5).

In our present study, cold challenge did not provoke a significant change in salivary $\mathrm{ET}_{1-21}$ in either the controls or the vibration-exposed workers with or without VWF symptoms. By contrast, other studies have found a significant increase in plasma $\mathrm{ET}_{1-21}$ concentrations after cold provocation in either vibration-exposed persons or VWF cases $(4,9)$. Apart from the different medium in which $\mathrm{ET}_{1-21}$ was measured (saliva versus plasma), it is possible that a difference in the methods used for the cold provocation testing may account for the discrepancy between the study results. In our investigation, only one finger was cooled $\left(10^{\circ} \mathrm{C}\right.$ for 5 minutes $)$, while in the other studies both hands were immersed in water at 6-10 ${ }^{\circ} \mathrm{C}$ for 5-6 minutes. The release of $\mathrm{ET}_{1-21}$ seems to be associated with the degree of severity of the cooling procedure for both controls and patients with Raynaud's phenomenon (21).

It is worth noting that the inconsistencies between studies of $\mathrm{ET}_{1-21}$ and VWF reflect those observed in several investigations of $\mathrm{ET}_{1-21}$ in primary Raynaud's phenomenon or secondary Raynaud's phenomenon of nonoccupational origin (eg, in systemic sclerosis). A wide range of findings for circulating $\mathrm{ET}_{1-21}$ in both baseline conditions and after a cold challenge (increased or decreased levels, no change) have been reported for patients with Raynaud's phenomenon when they were compared with healthy controls (21-24). As a result, some authors have questioned the possible role of $\mathrm{ET}_{1-21}$ in the pathogenesis of Raynaud's phenomenon $(23,24)$. However, since $\mathrm{ET}_{1-21}$ has a potent and sustained vasoconstrictor activity and potentiates the vasoconstriction evoked by either vasoactive hormones or neurotransmitters released from adrenergic nerve endings, various investigators believe that this vasopeptide may play a role in the pathogenesis of vasospastic syndromes in humans (25).

Although the presence of immunoreactive endothelin in human saliva has been reported since 1991 (26), only recently has the measurement of salivary 
$\mathrm{ET}_{1-21}$ concentrations been used to assist in the detection and assessment of the severity of various oral and systemic diseases (12-14). Endothelin is synthesized predominantly by the vascular endothelium and released towards the vascular smooth muscle cells and the interstitial tissues. It has been reported that salivary and plasma endothelin concentrations are positively correlated, but that $\mathrm{ET}_{1-21}$ content in saliva is greater than in plasma, probably because the secretion of the peptide is preferentially abluminal toward the salivary ducts $(10$, 12). Moreover, salivary $\mathrm{ET}_{1-21}$ appears to respond to the same stimuli that lead to an increase in plasma $\mathrm{ET}_{1-21}$ levels. These findings seem to suggest that saliva may be an appropriate biological fluid with which to assess the activation of the endothelin system $(10,12)$.

A personal search in PubMed resulted in no published study when the key terms "salivary endothelin" "occupation", and "vibration" were used. A recent review reported that only 11 papers used saliva biomarkers in areas of occupational and environmental health research (11). This finding is surprising because saliva sampling is a simple and noninvasive method, convenient for identifying a wide range of diagnostic biomarkers and easy to use in occupational epidemiologic surveys conducted in the field. This study of forestry workers showed, for the first time, a significant relation between salivary $\mathrm{ET}_{1-21}$ and vibration-induced symptoms (VWF) and signs $\left(\mathrm{FSBP} \%_{10^{\circ}}\right.$ ) of peripheral vascular disorders, as well as an association with indicators of daily $[\mathrm{A}(8)]$ and cumulative (total operating time) vibration exposure.

The synthesis of endothelin is regulated by several biochemical or physical signals, for example, mechanical shear stress. There is evidence that vibration can induce severe shear stress in arterial walls, and this occurrence may lead to endothelial damage or dysfunction, which may be related to the vascular disorders observed in workers using vibrating tools (27). In an in vitro investigation of the biomechanical signal transduction of vibration in human endothelial cells, vibration-induced fluid oscillations significantly increased the release of $\mathrm{ET}_{1-21}$ in a comparison with steady flow (28). In another experimental study, the expression of ET mRNA (messenger ribonucleic acid) in endothelial cells was upregulated in response to vibrational mechanical forces (29). In dermal microvascular endothelial cells exposed to vibration similar to that found at the workplace $(125 \mathrm{~Hz}$ with an acceleration of $10 \mathrm{~m} / \mathrm{s}^{2}$ ), the $\mathrm{ET}_{1-21}$ concentrations were greater in the supernatant of vibrated cells than in control cells (30). In an in vivo study of rabbits exposed to vibration at different intensities and for different exposure periods, the plasma $\mathrm{ET}_{1-21}$ levels increased and the plasma nitric oxide levels decreased with increasing vibration exposure in the experimental groups when they were compared with the control group (31).
These findings tend to give biological plausibility to a possible role of $\mathrm{ET}_{1-21}$ as a mediator of the exaggerated digital vasoconstriction occurring in workers exposed to hand-transmitted vibration.

The pathophysiology of VWF is complex and multifactorial, since there is experimental and clinical evidence that both adrenergic mechanisms (increased central sympathetic vasoconstrictor reflex, increased expression and activity of $\alpha_{2}$ adrenoreceptors) and nonadrenergic mechanisms (imbalance between endothelium-derived vasocontracting and relaxing factors, loss of digital cutaneous perivascular nerves containing vasoactive peptides, abnormalities of blood rheology) are involved in the excessive digital vasospasm induced by exposure to hand-transmitted vibration $(1-3,32,33)$. Therefore, it is unlikely that a single factor can play a dominant role in the pathogenesis of VWF. Nevertheless, the persisting vasoconstrictor after-effects observed in the finger circulation of experimental subjects during recovery periods after exposures to hand-transmitted vibration with different frequencies, magnitudes, and durations $(2,3)$ may suggest a possible implication of $\mathrm{ET}_{1-21}$ in vibration-induced vascular disorders since this vasopeptide has been shown to produce a powerful and prolonged constriction of blood vessels both in vitro and in vivo.

Our study has some potential limitations. The response rate was lower in the exposed workers than in the controls (75\% versus $93 \%$ ), even though the number of participants among the exposed was higher than in previous studies (4-7). Moreover, the number of controls was high in comparison with those investigated in other studies of salivary $\mathrm{ET}_{1-21}(12-14)$. The exposed and control workers were similar with respect to individual characteristics, were members of the same public company, and resided in the same geographic area, so that differences were not expected with respect to these variables. Internationally accepted methods and criteria for the diagnosis of VWF (16), cold test procedure (18), and the evaluation and assessment of vibration exposure $(19,20)$ were used to minimize biases in the classification of disease status and errors in the ascertainment and quantification of the risk arising from hand-transmitted vibration. In our study, a medical interview, physical examination, cold test, and saliva sample collection were performed by a single examiner. The adoption of standardized diagnostic procedures should have guaranteed consistency in the collected data and therefore minimized the within-examiner variability. An exaggeration of VWF symptoms cannot be ruled out among the exposed workers, but the observed prevalence $(11 \%)$ tended to exclude an overestimation of the disorder. However, despite the small number of VWF cases $(\mathrm{N}=6)$, the differences in the before and after cold-challenge salivary $\mathrm{ET}_{1-21}$ concentrations between 
the controls and the VWF workers were large enough to reach the limit of statistical significance.

Even though nested in a 4-year prospective cohort survey (15), the design of our study was cross-sectional, so that the temporal relationship between cause and effect could not be ascertained. In this study, the VWF cases had greater daily and cumulative vibration exposures than the noncases, even though the difference was not significant. Thus it is difficult to speculate whether it was the vibration exposure or the case status that was associated with the salivary $\mathrm{ET}_{1-21}$ concentration. As a result, the significant relations between the cold response of digital arteries, vibration exposure, and salivary $\mathrm{ET}_{1-21}$ concentrations should be interpreted with caution and considered as a contribution to the understanding of the pathophysiological mechanisms underlying VWF.

\section{Concluding remarks}

This study showed significant associations between the cold response of digital arteries, vibration exposure, and salivary $\mathrm{ET}_{1-21}$ concentration in a group of forestry workers using vibrating tools. Since $\mathrm{ET}_{1-21}$ can induce a powerful and long-lasting constriction in human vessels, these findings may suggest a possible role of this vasopeptide in the pathogenesis of VWF. The measurement of $\mathrm{ET}_{1-21}$ concentrations in saliva is a simple and noninvasive method with which to monitor the activity of this biomarker in the area of vibration research.

\section{Acknowledgments}

This research was partially supported by the European Commission under the Quality of Life and Management of Living Resources programme-project QLK42002-02650 (VIBRISKS).

\section{References}

1. Olsen N. Centrally and locally mediated vasomotor activities in Raynaud's phenomenon. Scand J Work Environ Health. 1987;13:309-12.

2. Olsen N. Vibration after effects on vasoconstrictor response to cold in the normal finger. Eur J Appl Physiol. 1993;66:246-8.

3. Bovenzi M, Lindsell CJ, Griffin MJ. Acute vascular response to the frequency of vibration transmitted to the hand. Occup Environ Med. 2000;57:422-30.

4. Taccola A, Aprile C, Bacchella L. Occupational syndromes of the extremities. The role of endothelin in the cold-test vasospasm: a pathogenetic hypothesis. G Ital Med Lav. 1991;13:71-5.

5. McKenna K, McGrann S, Blann AD, Allen JA. An investigation into acute vascular effects of riveting. $\mathrm{Br} \mathrm{J}$ Ind Med.
1993;50:160-6.

6. Kohout J, Topolčan $\mathrm{O}$, Bejčková $\mathrm{H}$. The serum level of endothelin in patients with hand-arm vibration syndrome. Cent Eur J Public Health. 1995;3 suppl:43-4.

7. Nakamura H, Ariizumi M, Okazawa T, Nagase H, Yoshida M, Okada A. Involvement of endothelin in peripheral circulatory change induced by hand-arm vibration. Cent Eur J Public Health. 1995;3 suppl:27-30.

8. Toibana N, Kanazuka M, Shigekiyo T. High level of plasma thrombomodulin (TM) concentration and correlation with endothelin (ET)-1 in vibration-exposed workers. Cent Eur J Public Health. 1995;3 suppl:40-2.

9. Palmer KT, Mason H. Serum endothelin concentrations in workers exposed to vibration. Occup Environ Med. 1996;53:118-24.

10. Xiang S, Denver R, Bailey M, Krum H. Physiological determinants of endothelin concentration in human saliva. Clin Chem. 2003;49:2012-9.

11. Koh DS-Q, Koh GC-H. The use of salivary biomarkers in occupational and environmental medicine. Occup Environ Med. 2007;64:202-10.

12. Denver R, Tzanidis A, Martin P, Krum H. Salivary endothelin concentrations in the assessment of chronic heart failure. Lancet. 2000;355:468-9.

13. Lam HC, Lo GH, Lu CC, Chu CH, Sun CC, Chuang MJ, et al. Salivary immunoreactive endothelin in patients with upper gastrointestinal diseases. J Cardiovasc Pharmacol. 2004;44: S413-7.

14. Pickering V, Jordan RC, Schmidt BL. Elevated salivary endothelin levels in oral cancer patients-a pilot study. Oral Oncol. 2007;43:37-41.

15. Humanvibration.com [homepage on the Internet]. Southampton (United Kingdom): Human Factors Research Unit, Institute of Sound and Vibration Research, University of Southampton [updated 28 February 2007; cited 7 October 2007]. Available from: http://www.humanvibration.com/vibrisks/index.html.

16. Olsen N, Hagberg M, Ekenvall L, Futatsuka M, Harrison J, Nasu Y, et al. Clinical and laboratory diagnostics of vascular symptoms induced by hand-arm vibration: report from discussions in a working group. Stockholm: Arbetarskyddsverket; 1995. Arbete och Hälsa, volume 5, p 181-6.

17. Maricq HR, Weinrich MC. Diagnosis of Raynaud's phenomenon assisted by color charts. J Rheumatol. 1998;15:454-9.

18. International Organization for Standardization (ISO). Mechanical vibration and shock - cold provocation tests for the assessment of peripheral vascular function, part 2: measurement and evaluation of finger systolic blood pressure. Geneva: ISO; 2005. ISO 14835-2.

19. International Organization for Standardization (ISO). Mechanical vibration - measurement and evaluation of human exposure to hand-transmitted vibration, part 1: general requirements. Geneva: ISO; 2001. ISO 5349-1.

20. Directive 2002/44/EC of the European Parliament and the Council of 25 June 2002 on the minimum health and safety requirements regarding the exposure of workers to the risks arising from physical agents (vibration) (sixteenth individual Directive within the meaning of Article 16(1) of Directive 89/391/EEC). Off J Eur Communities. L 117/13, 6.7.2002.

21. Zamora MR, O'Brien RF, Rutherford RB, Weil JV. Serum endothelin-1 concentrations and cold provocation in primary Raynaud's phenomenon. Lancet. 1990;336:1144-7.

22. Kanno K, Hirata Y, Emori T, Ohta K, Shichiri M, Shinohara $\mathrm{S}$, et al. Endothelin and Raynaud's phenomenon. Am J Med. 1991;90:130-2. 
23. Bottomley W, Goodfield M. A pathogenic role for endothelin in Raynaud's phenomenon? Acta Derm Venereol. 1994;74:433-4.

24. Smyth AE, Bell AL, Bruce IN, McGrann S, Allen JA. Digital vascular responses and serum endothelin-1 concentrations in primary and secondary Raynaud's phenomenon. Ann Rheum Dis. 2000;59:870-4

25. Yang Z, Richard V, von Segesser L, Bauer E, Stulz P, Turina M, et al. Threshold concentrations of endothelin-1 potentiate contractions to norepinephrine and serotonin in human arteries: a new mechanism of vasospasm? Circulation. 1990;82:188-95.

26. Lam HC, Takahashi K, Ghatei MA, Warrens AN, Rees AJ, Bloom SR. Immunoreactive endothelin in human plasma, urine, milk, and saliva. J Cardiovasc Pharmacol. 1991;17 suppl 7:S390-3.

27. Nerem RM. Vibration-induced arterial shear stress: the relationship to Raynaud's phenomenon of occupational origin. Arch Environ Health. 1973;26:105-10.

28. White CR, Haidekker MA, Stevens HY, Frangos JA. Extracellular signal-regulated kinase activation and endothelin-1 production in human endothelial cells exposed to vibration. J Physiol. 2004;555.2:565-72.
29. Ziegler T, Bouzourene K, Harrison VJ, Brunner HR, Hayoz D. Influence of oscillatory and unidirectional flow environment on the expression of endothelin and nitric oxide synthase in cultured endothelial cells. Arterioscler Thromb Vasc Biol. 1998;18:686-92.

30. Cezeaux JL, Lindsley WG. Effect of vibration on endothelin1 production by dermal microvascular endothelial cells. Ann Biomed Eng. 2000;28 suppl 1:S-75.

31. Lin L, Wang L, Zhu F, Zeng X. Effects of local vibration on the levels of plasma endothelin and nitric oxide in rabbits [in Chinese, with English abstract]. Wei Sheng Yan Jiu. 2000;29:10-1

32. Goldsmith PC, Molina FA, Bunker CB, Terenghi G, Leslie TA, Fowler CJ, et al. Cutaneous nerve fiber depletion in vibration white finger. J R Soc Med. 1994;87:377-81.

33. Krajnak K, Dong RG, Flavahan S, Welcome D, Flavahan NA. Acute vibration increases $\alpha_{2 c}$-adrenergic smooth muscle constriction and alters thermosensitivity of cutaneous arteries. J Appl Physiol. 2006;100:1230-7.

Received for publication: 8 October 2007 